\title{
Nanofabrication of Diamond-like Carbon Templates for Nanoimprint Lithography
}

\author{
L. Tao, S. Ramachandran, C. T. Nelson, T. H. Lee, L. J. Overzet, M. J. Goeckner, M. Kim, G. S. \\ Lee, and $\mathrm{W}$. Hu \\ Department of Electrical Engineering, University of Texas at Dallas, Richardson, TX, 75083
}

\begin{abstract}
Diamond like carbon (DLC) films were deposited on Si and then patterned to form $40 \mathrm{~nm}$ features as nanoimprint templates. A plasma enhanced chemical vapor deposition (PECVD) system with $\mathrm{CH} 4$ precursor was used to deposit DLC films on Si and quartz substrates. These films were then characterized using Raman spectroscopy, atomic force microscopy (AFM), nanoindentation, and contact angle measurement. By varying the RF power and pressure of the PECVD, DLC films with good uniformity, smooth surfaces ( $<0.2 \mathrm{~nm}$ RMS), low surface energy $\left(\sim 40 \mathrm{~mJ} / \mathrm{m}^{2}\right)$, and high hardness ( $\left.22 \mathrm{GPa}\right)$ were achieved. Nanoimprint lithography and liftoff process were used to pattern Cr mask on DLC films. An inductively coupled plasma (ICP) etching process was performed with $\mathrm{CF}_{4}$ to transfer the patterns into the DLC films to form nanostructured template for nanoimprint. Water contact angles on the patterned DLC templates were measured and were stable at about $70^{\circ}$ under thermal annealing at $180^{\circ} \mathrm{C}$ for more than 12 hours. With these DLC templates, UV and reversal UV nanoimprint lithography were carried out on SU-8 at typical imprint conditions. The fidelity of pattern-transfer was investigated. These experimental results indicate that DLC is an excellent material for nanoimprint templates because of its high wear resistance, robust low surface energy, UV transparency, and ease of patterning.
\end{abstract}

\section{INTRODUCTION}

Nanoimprint lithography (NIL) is basically a pressure induced transfer of topographic patterns from a rigid template into a thermoplastic polymer film heated above its glass transition temperature $\left(\mathrm{T}_{\mathrm{g}}\right)$, or into UV curable polymers under UV exposure. Fine structures as small as a few nanometers have been fabricated in this way [1]. One of the key challenges of nanoimprint is how to make defect-free templates that offer robust low surface energy for template-substrate separation, long lifetime, and low fabrication cost [2]. However, due to the physical contact during imprinting, the conventional silicon and quartz templates suffer serious wearing damage after a certain number of imprint cycles, which shortens template life time and increases manufacturing cost [3,4]. To alleviate this problem, hard material such as diamond [5] and $\mathrm{SiC}$ [6] has been investigated to make high wear resistance templates. But both have major disadvantages: diamond is too expensive and too slow to grow while $\mathrm{SiC}$ is not transparent to UV light. In last decades, diamond-like carbon (DLC), a hard amorphous carbon (a-C), or hydrogenated amorphous carbon (a-C:H) [7] has been studied as a protective coating layer. Previously, we have systematically studied the property of DLC films and found it is an ideal material for NIL templates [8]. Here we demonstrate the fabrication of sub-100 nm DLC nanoimprint templates and successful UV and newly developed reversal-UV nanoimprint [9] with these DLC templates on SU-8 resists. 


\section{EXPERIMENTS}

DLC films were deposited on Si substrates in a capacitively coupled reactor with our own modification of the configuration of electrodes in the previous study [8], which allows the flexible control of most parameters of the plasma enhanced chemical vapor deposition (PECVD) process. Under typical deposition conditions: rf power of $100-450 \mathrm{~W}$ resulting in a dc bias between -100 and $-400 \mathrm{~V}$, pressure of 30-100 mTorr, and deposition rate of $\sim 10 \mathrm{~nm} / \mathrm{min}$, a DLC film layer of $\sim 300 \mathrm{~nm}$ was deposited onto the Si substrates using a mixture of argon and methane as a precursor.

After the deposition of DLC films, a series of material characterizations were carried out. Raman spectra were collected at multiple points on a single sample using a Jobin Yvon Labram high resolution micro-Raman spectrometer with laser excitation at $633 \mathrm{~nm}$. The spectra were fitted with disordered peak (D-peak) and graphitic peak (G-peak) to determine the structural property of the DLC films deposited. Surface roughness of the DLC film was measured using contact mode atomic force microscopy (AFM). The hardness and wear testing of the DLC film was measured using a Hysitron nanoindentor11(is nanoindentor11 or nanoindentor 11) with 75 $\mathrm{nm}$ wide diamond tips and maximum loads of $100 \mu \mathrm{N}$ and on the same nanoindentor using a 150 $\mathrm{nm}$ diameter diamond tip at normal loads of $40 \mu \mathrm{N}$ to scan $5 \times 5 \mathrm{~m}^{2}$ areas respectively. Contact angle for DI water and ethylene glycol were measured on a Ramè Hart manual contact angle goniometer to investigate the surface energy of the DLC film. In addition, the annealing effect at $180^{\circ} \mathrm{C}$ in vacuum oven for $15 \mathrm{~min}$ to 12 hour of the DLC film surface energy on quartz substrate was also studied by measuring the contact angle for DI water.

Nanoimprint lithography and electron beam lithography were performed to generate nanoscale patterns in the PMMA resist that was spincoated on the DLC films. A metal lift-off process was performed to transfer these nanofeatures onto the $\mathrm{Cr}$ layer, which is used as a mask for the following ICP reactive ion etching using $\mathrm{CF}_{4}$ at pressures between 5 and 15 mTorr, bias power of $100 \mathrm{~W}$, and ICP power of $400 \mathrm{~W}$ for 1-2 minutes. After etching, the Cr residue was stripped away and DLC NIL templates were evaluated by AFM and SEM. At last, both the conventional UV nanoimprint and reversal UV nanoimprint was performed at $70{ }^{\circ} \mathrm{C}$ under 6 MPa for 10 min with 1s UV exposure on SU-8 coated glass substrates. UV light was induced through the glass substrates. Nanostructures on the templates and on the SU-8 layers were imaged using AFM and SEM.

\section{RESULTS AND DISCUSSION}

\section{Structural and mechanical properties of the DLC film}

The raw Raman spectrum, as shown in Fig.1, confirms that the film structure is similar to that of DLC and the absence of a sloping photoluminescence background confirms that it is closer to diamondlike a-C:H, as opposed to a polymerlike a-C:H [10].

The variations in the fitting parameters $(\mathrm{G}$ - and D-peak center positions, their widths and area ratios) that enable one to qualitatively estimate changes in the ratio of sp3 bonded carbon to sp2 bonded carbon. These parameters have been studied as functions of PECVD power and 
pressure [8]. From the Raman data, these films were rather more diamondlike than graphitic atomic structure in nature.

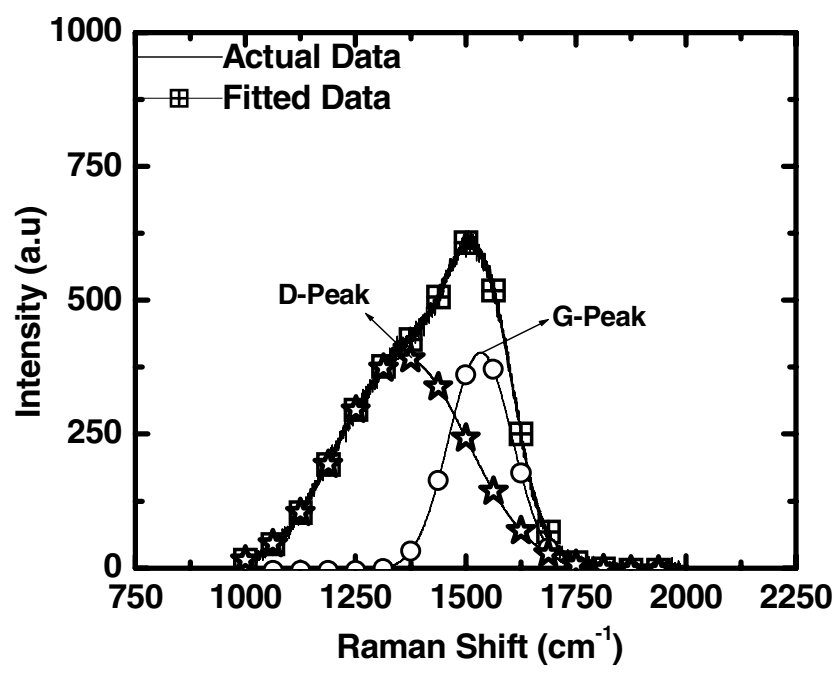

Figure 1. A typical Raman spectra of the DLC film deposited at $300 \mathrm{~W}$ rf power and 50 mTorr chamber fitted with disordered carbon peak (D peak) and graphite peak (G peak).

Mechanical testing measurements indicated that these DLC films ranged from 18 to 23 $\mathrm{GPa}$ and that larger deposition powers resulted in harder films. The DLC templates were found to be about 2 times harder than $\mathrm{Si}(10.6 \mathrm{GPa})$ and quartz $(9.3 \mathrm{GPa})$. The abrasive wear of DLC films on $\mathrm{Si}$ and quartz were investigated. As shown in Fig. 2, DLC films showed wear depths of about $2.00 \mathrm{~nm}$, while the wear depth of quartz was $6.39 \mathrm{~nm}$ under the same force load of 40 $\mu \mathrm{N}$ on a $150 \mathrm{~nm}$ diamond tip. The wear resistance of a DLC template is 3 times better than quartz and almost 2 times better than $\mathrm{Si}$.

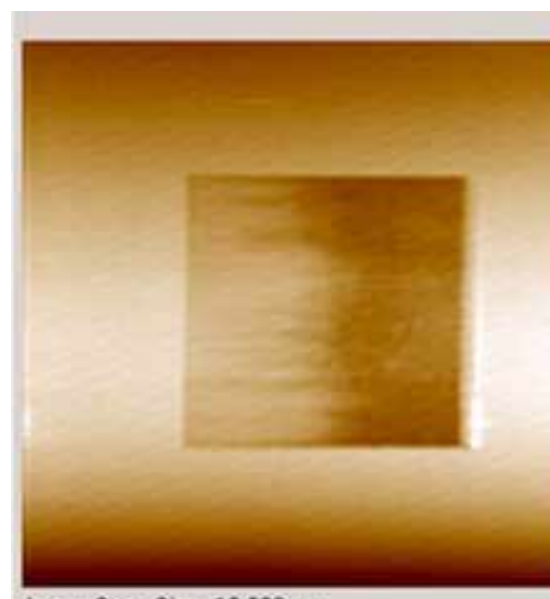

Imsoge Scon Sice: $10.000 \mathrm{~mm}$

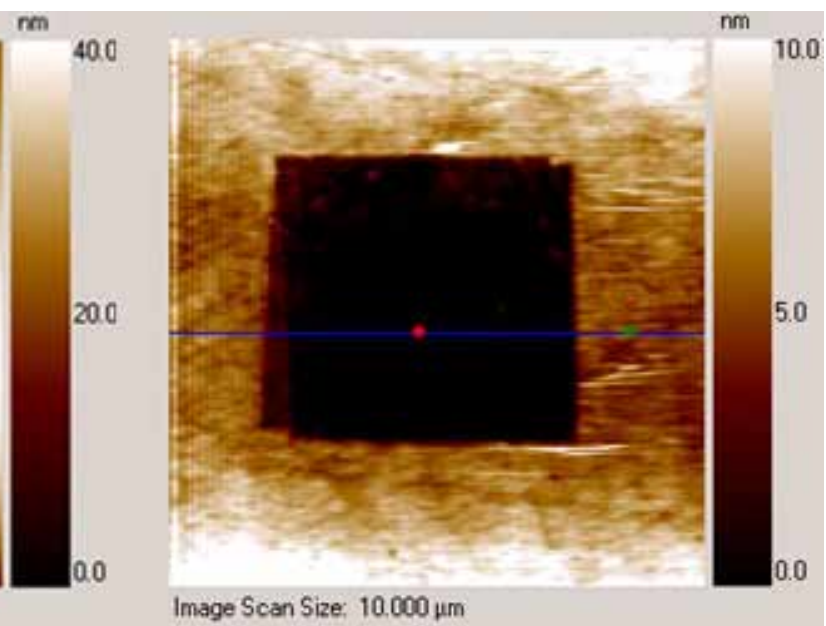

Image Scan Size: $10.000 \mu \mathrm{m}$

Figure 2. Topographical in-situ AFM image of DLC films on Si (left) and a bare quartz substrate (right) after pin-on-plate wear testing with $40 \mu \mathrm{N}$ load on a $150 \mathrm{~nm}$ diamond tip.

\section{$\underline{\text { Surface energy property(maybe properties) }}$}


The surface energies of the material used as a template in NIL applications play a crucial role in defining the fidelity of the pattern transfer. Contact angle measurements were performed with water and ethylene glycol on the DLC films, and the polar and dispersive components of the surface energy were calculated using the two-liquid method [11]. The calculated surface energies are shown in Table I, which shows the DLC films have a surface energy of $35-50 \mathrm{~mJ} / \mathrm{m}^{2}$. $\quad \mathrm{CF}_{4}$ etching reduced the DLC surface energy from $49 \mathrm{~mJ} / \mathrm{m}^{2}$ to lower than $40 \mathrm{~mJ} / \mathrm{m}^{2}$ due to the formation of a thin $\mathrm{CFx}$ (should there be a 4 here) film over the a-C:H film. The thermal annealing of the DLC films deposited with varying PECVD power is studied for its effect on water contact angle, as shown in Fig 3. The water contact angles on the DLC films were not reduced by this thermal annealing process even at $180^{\circ} \mathrm{C}$ for more than 12 hours. This satisfies the requirements of thermal nanoimprint process.

Table I. Surface energies of DLC films before and after ICP etch.

\begin{tabular}{lcllll}
\hline & \multicolumn{2}{l}{$\begin{array}{l}\text { contact angle } \\
\left({ }^{\circ}\right)\end{array}$} & \multicolumn{2}{c}{$\begin{array}{l}\text { surface energy* } \\
\left(\mathrm{mJ} / \mathrm{m}^{2}\right)\end{array}$} \\
\cline { 2 - 6 } ICP etch conditions & $\mathrm{H}_{2} \mathrm{O}$ & $\begin{array}{l}\text { Ethylene } \\
\text { glycol }\end{array}$ & $\left.\gamma^{\mathrm{d}}+\gamma^{\mathrm{p}}\right)$ \\
\hline Before etch & 57.0 & 52.5 & 45.8 & $\gamma^{\mathrm{d}}$ & $\gamma$ \\
$\mathrm{CF}_{4}, 20$ mTorr & 89.5 & 55.0 & 1.4 & 36.6 & 38.0 \\
$\mathrm{CF}_{4}, 60$ mTorr & 90.0 & 61.0 & 2.7 & 28.0 & 30.7 \\
Surface energy $\gamma$ is the sum of $\gamma^{\mathrm{d}}$ (dispersion component) and $\gamma^{\mathrm{p}}$ (polar component)
\end{tabular}

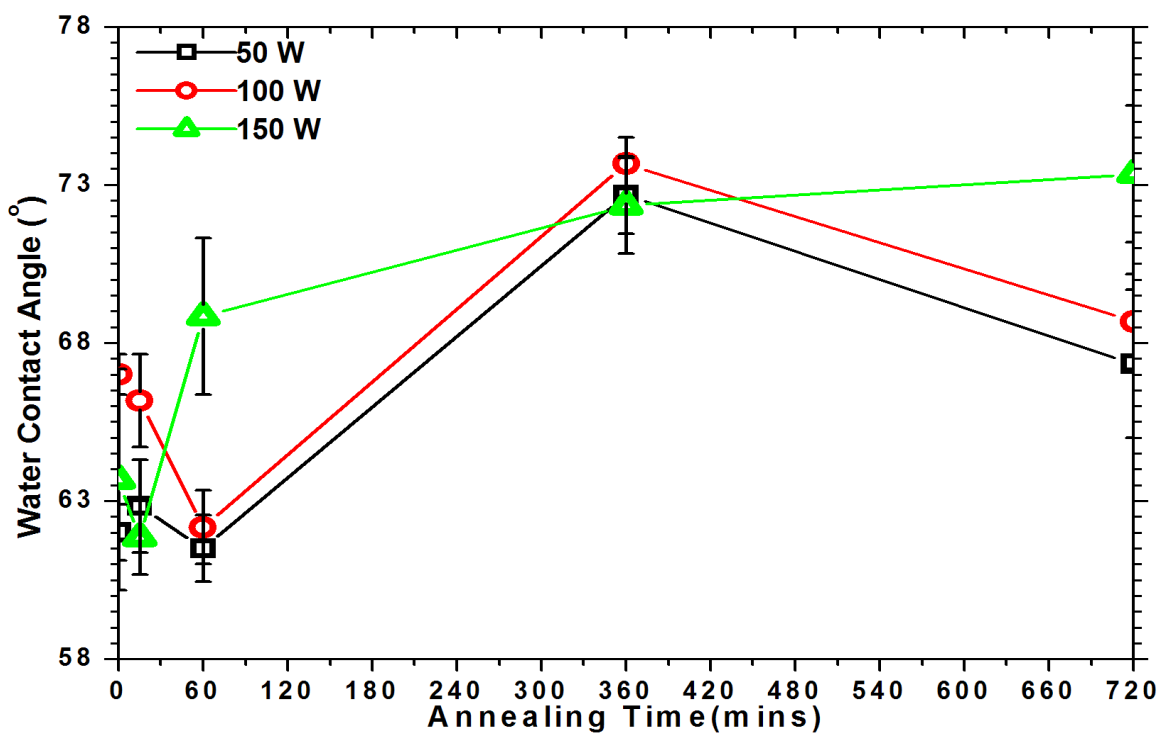

Figure 3. Effect of thermal annealing $\left(180^{\circ} \mathrm{C}\right)$ on the water contact angle of the DLC films deposited with varying plasma power $(50-150 \mathrm{~W})$.

Fabrication of DLC templates and imprint testing 
Nanoimprint lithography and electron beam lithography were used to pattern PMMA. A liftoff process generated $\mathrm{Cr}$ nanostructures on the DLC films, which were used as etching masks for an ICP etching process with $\mathrm{CF}_{4}$ to form nanostructures in the DLC films. The etch rate of DLC was about $100 \mathrm{~nm} / \mathrm{min}$. Fig. 4 shows the cross-sectional view of a DLC template with $200 \mathrm{~nm}$ lines etched for 2 mins. The RMS roughness of the DLC film before and after the ICP etch was nearly the same $\sim 0.1 \mathrm{~nm}$.

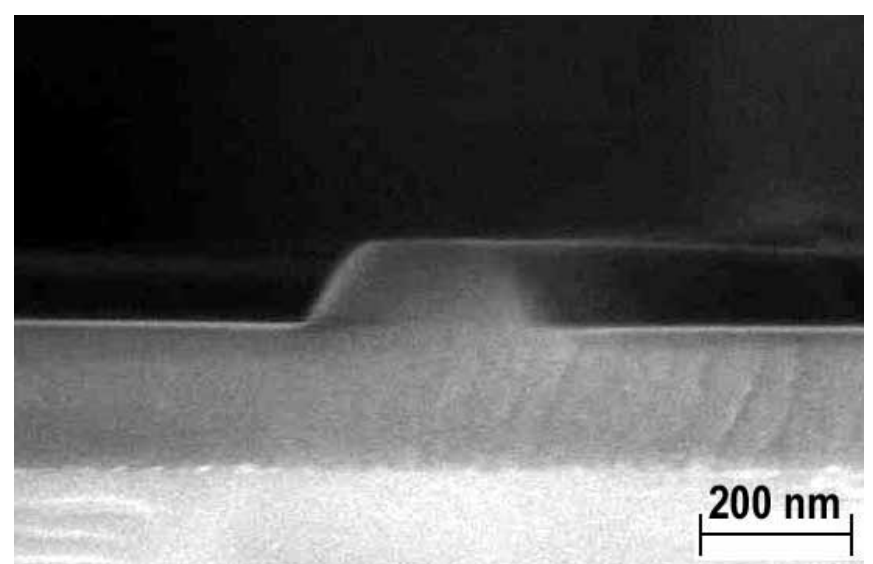

Figure 4. The SEM cross sectional view of the DLC mold etched by ICP etch using 30 SCCM $\mathrm{CF}_{4}$ at 5-15 mTorr for $2 \mathrm{~min}$. This kind of cross section is a benefit to the demolding after the nanoimprint.

UV and reversal UV imprint process were carried out with the patterned DLC template at $70{ }^{\circ} \mathrm{C}$ and $6 \mathrm{MPa}$ for $10 \mathrm{~min}$ in 300 -nm-thick SU-8 on glass substrates with 1s UV exposure (UV was induced through the glass substrates). Fig. 5 shows the AFM images of $40 \mathrm{~nm}$ line and space structures on the DLC templates and also UV imprints in SU-8, indicating good fidelity during imprint process.

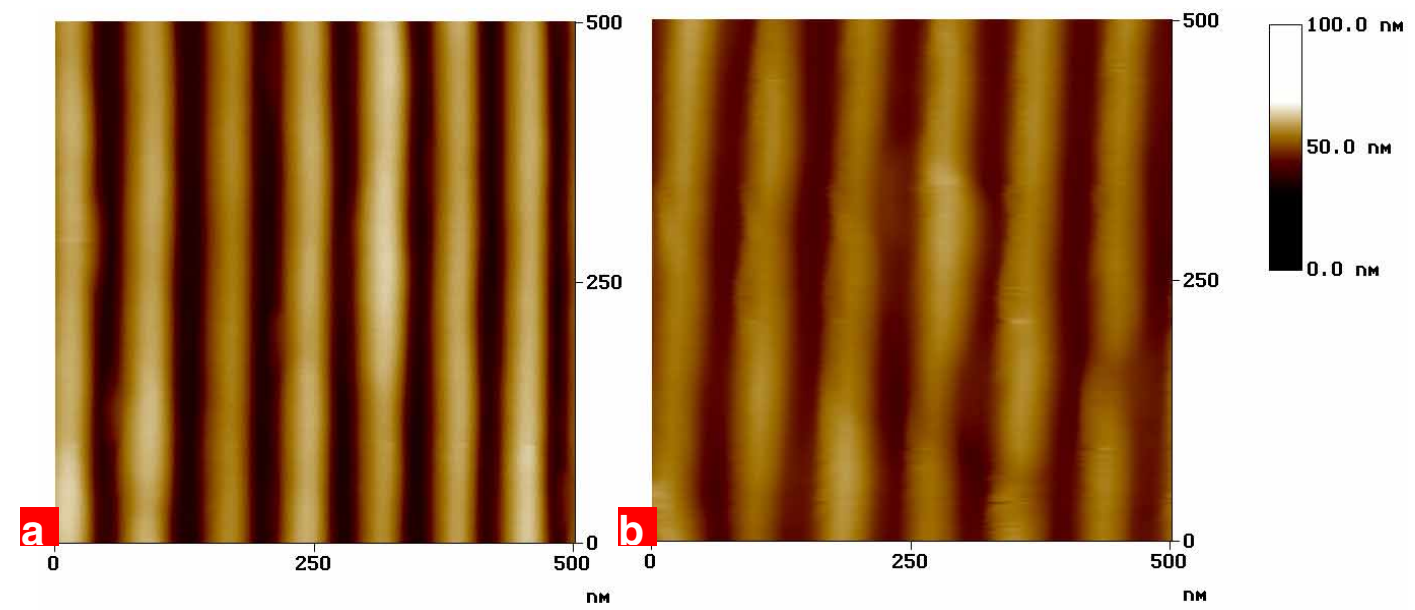

Figure 5. AFM images of a) the DLC template with $40 \mathrm{~nm}$ lines and space and b) SU8 imprinted gratings.

\section{CONCLUSIONS}


PECVD Deposition and nanopatterning of DLC films were demonstrated as scratchproof nanoimprint templates that offer robust low surface energy for both thermal and UV nanoimprint processes. In particular, the natural low surface energy of the DLC films allows spincoating of SU-8 on the template for reversal UV imprints [9]. With the DLC templates, reversal UV nanoimprint was used pattern SU-8 gratings with $40 \mathrm{~nm}$ linewidth (80 nm pitches) and $100 \mathrm{~nm}$ depth.

\section{ACKNOWLEDGMENTS}

The authors would like to thank Dr. Wei Wu of Hewlett-Packard Inc. for some patterning of $\mathrm{Cr}$ structures on the DLC films; Dr. Bruce Gnade, Unnat Bhansali and Dr. JiYoung Kim, Bongki Lee for the help on the AFM imaging; and Tao Zheng, Yuming Ai for the preparation of the sample cross-sections using focus ion beam system.

\section{REFERENCES}

1. M. D. Austin, H. X. Ge, W. Wu, M. T. Li, Z. N. Yu, D. Wasserman, S. A. Lyon, and S. Y. Chou, Appl. Phys. Lett. 84 (26), 5299 (2004).

2. 2005 International Technology Roadmap for Semiconductors, see http:// www.public.net/itrs

3. T. Bailey, B. J. Choi, M. Colburn, M. Meissl, S. Shaya, J. G. Ekerdt, S. V. Sreenivasan, and C. G. Willson, J. Vac. Sci. Technol. B 18, 3572 (2000)

4. R. W. Jaszewski, H. Schift, B. Schnyder, A. Schneuwly, and P. Groning, Appl. Surf. Sci. 143, 301 (1999)

5. K. A. Lister, S. Thoms, D. S. Macintyre, C. D. W. Wilkinson, J. M. R. Weaver, and B. G. Casey, J. Vac. Sci. Technol. B 22, 3257 (2004).

6. S. W. Pang, T. Tamamura, M. Nakao, A. Ozawa, and H. Masuda, J. Vac. Sci. Technol. B 16, 1145 (1998).

7. J.Robertson, Pure \& Appl. Chem., Vol. 66, No. 9, pp. 1789-1796, 1994.

8. S. Ramachandran, L. Tao, T. H. Lee, S. Sant, L. J. Overzet, M. J. Goeckner, M. J. Kim, G. S. Lee, and W. HuJ. Vac. Sci. Technol. B, Vol. 24, No. 6, Nov/Dec 2006

9. W. Hu , B. Yang, C. Peng, and S. W. Pang, J. Vac. Sci. Technol. B. pp. 2225-2229, 2006.

10. C. Casiraghi, F. Piazza, A. C. Ferrari, D. Grambole, and J. Robertson, Diamond Relat. Mater. 14, 1098 (2005)

11. D. K. Owens and R. C. Wendt, J. Appl. Polym. Sci. 13, 1741 (1969). 